\title{
TESTING NON-LINEAR EFFECT OF URBANIZATION ON ECONOMIC GROWTH IN CHINA - BASED ON THE ASPECT OF FINANCIAL DEEPENING
}

\author{
Xinguang $\mathrm{LI}^{1}-$ Ridong $\mathrm{HU}^{2}$ \\ ${ }^{1}$ Huaqiao University School of Economics and Finance, Quanzhou Fujian China 362021; \\ Wuyi University School of Business, Nanping Fujian China 354300. \\ E-mail: lixinguang001@163.com \\ ${ }^{2}$ Huaqiao University School of Economics and Finance, Quanzhou Fujian China 362021. \\ E-mail:j_rdhu@hqu.edu.cn (correspondingauthor)
}

\begin{abstract}
Smooth Transition Regression Model (STR) is applied to analyze the non-linear effect of urbanization on economic growth in this study. By collecting relevant variable data in 1978-2012, financial deepening is selected as the transition variable to construct the STR Model which could reflect the dynamic change of urbanizational economic growth effect. The result shows that urbanizational economic growth effect should present the characteristics of threshold and could be described with non-linear Smooth Transition Model (LSTR1). Meanwhile, the urbanizational economic growth effect should reveal asymmetry, in which the research findings show contemporary financial deepening (FISt) as a factor. Specifically, the linear feature appears when the FISt is lower than 0.3792 (before 1990), while it reveals non-linearity when the FISt exceeds 0.3792 (after 1990), and the non-linearity becomes the major factor in the urbanizational economic growth effect after 1990.
\end{abstract}

Keywords: economic growth, urbanization, financial deepening, Smooth Transition Regression Model (STR)

\section{INTRODUCTION AND LITERATURE REVIEW}

Guan Qing-you, a researcher of China Society of Economic Reform, pointed out, in May 2013, urbanization as a major opportunity for both China and the world; and urbanization was consistent with and inseparable from the "Chinese Dream" as well as the basis to fulfill Chinese Dream. Since the Third Plenary Session of the 18th Central Committee of the Chinese Communist Party, people-centered new-style urbanization has been progressively and orderly promoted in China in order to complete a beautiful blueprint of Chinese Dream as early as possible. To maximally develop the effect of urbanization on the promotion of economic 
growth, largely enhancing various work for domestic urbanization is the main emphasis for the latest government. Accordingly, it tends to study the relations between urbanization standard and economic growth which are highly concerned by the government and the academia.

Relative domestic research is organized as follows. 1. Research on the relations between urbanization and economic growth. Xu and Yuan (2013) applied chain rule to deduct the mechanism of urbanizational economic growth promotion and discovered that urbanization enhanced economic growth by accelerating factor accumulation. ${ }^{[1]}$ With the establishment of panel model, Chen Ke-jia et al. (2013) concluded that urbanization in Fujian Province promoted local economic growth through consumption and fixed assets investment. From the analyses of "town", "city", and "urbanization", Qi Xin (2013) mentioned that the economic growth effect under distinct levers was not completely the same. Shen Kun-rong et al. (2007) discovered that urbanization could affect economic growth through material capital, human capital, knowledge capital, and industrial structure path. Xiang Zheng et al. (2013) utilized heterogeneous random frontier model for discussing the pull effect of urbanization on economic growth in China. 2. Research on the relations between urbanization and finanacial development. Lu Ke et al. (2013) explored it from structural financing product innovation, special investment fund product innovation, and personal finance product innovation. Tian Dong-lin (2013) discussed the issue of serving new-style urbanization from the aspect of financial demands. Yuan Xiao-cu (2013) pointed out the contradiction in contemporary financial-support urbanization construction that the correspondent multifinancing system needed to be constructed. As the example of Guangdong, Fan Zhao-bin et al. (2004) considered that the lag of financial development would obstruct the development of urbanization. Nevertheless, the combination of financial support, urbanization, and economic growth was seldom analyzed. Wu Hong-ling (2012) preceded Regression Analysis of the relations of financial development and economic growth enhancing urbanization and discovered that the threshold function in financial development restrained the function of economic growth on urbanization. Meng Yin-li (2003) analyzed the relations between urbanization and economic growth, between urbanization and financial deepening and found out the bidirectional causality. Lucas (1988) applied Solow Growth Model to connect urbanization and economic growth for the first time. Ronald L. Moomaw et al. (1996) discovered that GDP per capita, industrialization, export orientation, and international aid could increase the urban weight, but not agricultural development. Henderson (2000) applied GMM to test the significant relations between economic growth and urbanization with the correlation coefficient 0.85 for developing countries. Henderson (2003) argued that the function of urbanization on enhancing economic growth was not single; once 
urbanization and city agglomeration exceeded a certain optimation, economic growth would be inhibited.

To sum up, the above literatures mainly discussed the pair relations between financial development and economic growth, urbanization and economic growth, and financial development and urbanization, but seldom the quantitative research on the combination of the three. In regard to quantitative research, VAR, cointegration, and Granger causality test were mainly applied to discuss the effect of urbanization on economic growth, while non-linear technique was seldom studied. Furthermore, few researchers took financial deepening factors into account when studying the contribution of urbanization to economic growth. Taking it as the cutting point, the path change of urbanization promotes economic growth in China since Chinese economic reform is reinspected from the aspect of financial deepening so as to observe the existence of non-linearity, the effect of such nonlinearity, the factor in the non-linear effect, and the effect of the financial deepening degree on the function path of urbanization. Such issues present real guiding meaning on the strategic arrangement in constructing new-style urbanization. Non-linear smooth transition (STR) therefore is applied to analyze such problems for the path selection of new-style urbanization in China and the reference of the government formulating specific financial support policies.

\section{THEORETICAL FRAMEWORK AND MODEL CONSTRUCTION}

\subsection{Theoretical analysis}

The basis of the relationship between urbanization and economic growth could be searched from the rural-urban migration model in Development Economics, which could be explained from two dimensions (Williamson 1988). On one hand, the highly increasing population relatively causing the shortage of rural land resulted in some labors turning to urban. On the other hand, the increasing urban economy also attracted rural labors. Lucas (2004) assumed that labors in an infinitively increasing economic system would migrate to modern departments (human resource-intensive) from traditional ones (land-intensive); particularly, urban migration was extremely important in enhancing new skills in modern industries. Zhou (1982) analyzed the relevant data of 157 nations and regions in 1977 and found out the non-linear relationship.

In the process of urbanization promoting economic growth, the support of financial development cannot be neglected. In 1970s, some economists (Shaw 1973; Mckinnon 1973) proposed the "financial deepening" theory through the research on financial development and economic growth in developing countries. 
The point emphasized that the government should release the restrictions to financial systems; interest rate was the key that increasing real interest rate to enhance people's activeness in savings would generate more capitals for investment, i.e. to implement financial deepening and promote economic growth with financial liberalization (Földvári et al. 2015). Urbanization could implement the resource reallocation and optimization through element movement and industrial transfer to eventually promote economic growth. Nevertheless, financial development would affect the allocation of savings and investment whose flow would affect urbanization development in various regions and influence the function efficiency of urbanization on economic growth. Since 1978, domestic financial reform has followed progressive characteristics, which do not show completely financial repression and have not achieved the financial liberalization promoted in western countries. The interference of the country in the financial system has experienced the development model of changing from planned finance to marketized finance. The interference degree of the government has turned from tight to loose that the financial market liberalization is gradually enhancing. In the promotion of economic system in domesic socialist market, financial deepening at different stages is distinct that it is wondered whether the mechanism and the direction in the process of urbanization functioning economic growth are also changed. The following issue is therefore proposed in this study.

Issue: The path of urbanization promoting economic growth would be restricted by the financial deepening degree.

Taking financial deepening as the transition variable, Smooth Transition Regression Model (STR) of urbanization and economic growth is constructed for testing.

\subsection{Brief description and construction of model}

Bryan Pele, a US geographer, found out the correlations between the economic development of a country and the urbanization degree. Following the idea, the successive researchers proceeded empirical tests. Xu Xiao-qin generalized that economic growth was driven by the direct and indirect factors of urbanization and deducted with $\mathrm{C}-\mathrm{D}$ production function for the final model: $\ln \mathrm{Y}=\mathrm{f}$ (URB; $\ln \mathrm{X}) ; \ln \mathrm{X}=\mathrm{f}(\mathrm{URB})$, in which $\mathrm{Y}$ was the gross output, URB the urbanization ratio, and $X$ the simple substitution of material capital, human capital, and $R \& D$ capital. Such two parts were further estimated. This study is expanded based on the previous research. 
Smooth Transition Regression Model (STR), a non-linear model, is the expansion of the transition regression model proposed by Quandt (1958). The standard STR model is depicted as below.

$$
y_{t}=\left\{\vartheta+\theta G\left(\gamma, c, s_{t}\right)\right\}^{\prime} z_{t}+u_{t}, \quad t=1, \ldots, T
$$

$\left.\mathrm{Z}_{\mathrm{t}}=\left(\mathrm{w}_{\mathrm{t}}, \mathrm{x}_{\mathrm{t}}\right)^{\prime}\right)$ is the vector of explanatory variable, $\mathrm{w}_{\mathrm{t}}{ }^{\prime}=\left(1, \mathrm{y}_{\mathrm{t}-1}, \ldots, \mathrm{y}_{\mathrm{t}-\mathrm{p}}\right)$ and $\mathrm{x}_{\mathrm{t}}$ $=\left(\mathrm{x}_{1 \mathrm{t}}, \ldots, \mathrm{x}_{\mathrm{kt}}\right)^{\prime}$ are exogenous variables, $\vartheta=\left(\vartheta_{0}, \vartheta_{1}, \cdots \vartheta_{m}\right)^{\prime}$ and $\theta=\left(\theta_{0}, \theta_{1}, \cdots \theta_{m}\right)^{\prime}$ are the vector of $(\mathrm{m}+1) * 1$ order matrix, $u_{t} \sim \operatorname{iid}\left(0, \sigma^{2}\right), \mathrm{G}\left(\Upsilon, \mathrm{c}, \mathrm{s}_{\mathrm{t}}\right)$ is the conversion function, $\Upsilon$ is a slope parameter, and $\mathrm{c}=\left(\mathrm{c}_{1}, \ldots, \mathrm{c}_{\mathrm{k}}\right)^{\prime}$ is a location parameter vector. In this model, $y_{t}$ is the gross output $\left(\mathrm{gdp}_{\mathrm{t}}\right), \mathrm{x}_{\mathrm{t}}$ is the urbanization ratio (urban $_{\mathrm{t}}$ ), and financial deepening (FIS $\mathrm{f}_{\mathrm{t}}$ ) is a transition variable.

STR model would present distinct forms with $\mathrm{G}\left(\Upsilon, \mathrm{c}, \mathrm{s}_{\mathrm{t}}\right)$ function. According to Granger and Terasvirta (1993), ${ }^{[21]} \mathrm{G}\left(\Upsilon, \mathrm{c}, \mathrm{s}_{\mathrm{t}}\right)$ could be divided into the following forms:

$$
G\left(\gamma, c, s_{t}\right)=\frac{1}{1+e^{-\gamma\left(s_{t}-c\right)}}, \gamma>0
$$

Equation (2) was named logistic STR (LSTR1), where G( $\left.\Upsilon, \mathrm{c}, \mathrm{s}_{\mathrm{t}}\right)$ was a monotonic increasing function; meanwhile, $\mathrm{G}\left(\Upsilon, \mathrm{c}, \mathrm{s}_{\mathrm{t}}\right)$ could be assumed as a nonmonotonic conversion function.

$$
G\left(\gamma, c, s_{t}\right)=\frac{1}{1+e^{-\gamma\left(s_{t}-c_{1}\right)\left(\mathrm{s}_{\mathrm{t}}-\mathrm{c}_{2}\right)}}, \gamma>0, c_{1} c_{2}
$$

In this case, the conversion function $\mathrm{G}\left(\Upsilon, \mathrm{c}, \mathrm{s}_{\mathrm{t}}\right)$ appeared non-monotonicity; regarding $\left(\mathrm{c}_{1}+\mathrm{c}_{2}\right) / 2$ point symmetry, $\mathrm{G} \rightarrow 1$ when $s_{t} \rightarrow \pm \infty$; and for $c_{1} \leq s_{t} \leq c_{2}, \mathrm{G} \rightarrow 0$ when $\Upsilon \rightarrow \infty$.

The following form appeared when the conversion function $G\left(\Upsilon, c, s_{t}\right)$ was an even function.

$$
G\left(\Upsilon, \quad c, s_{t}\right)=1-e^{-\gamma\left(s_{t}-c\right)^{2}}, \gamma>0
$$

Equation (4) was regarded as exponential STR Model (ESTR).

Terasvirta (1994) proposed a solution which could test non-linearity and judge the solution for specific model type. With a solution, third order Taylor series expansion was proceeded at $\Upsilon=0$ through the conversion function $\mathrm{G}$ and then substituted in equation (1) to acquire the following assistive regression equation.

$$
y_{t}=\beta_{0}^{\prime} z_{t}+\sum_{j=1}^{3} \beta_{j}^{\prime} z_{t} s_{t}^{j}+e_{t}^{*}, \quad \mathrm{t}=1, \ldots, \mathrm{T} ; \mathrm{Z}_{\mathrm{t}}=\left(1, \tilde{Z}_{t}\right)^{\prime} ; \mathrm{e}_{\mathrm{t}}^{*}=\mathrm{e}_{\mathrm{t}}+\mathrm{R}_{3}\left(\gamma, \mathrm{c}, \mathrm{s}_{\mathrm{t}}\right) \theta^{\prime} \mathrm{z}_{\mathrm{t}}
$$


$\mathrm{R}_{3}\left(\Upsilon, \mathrm{c}, \mathrm{s}_{t}\right)$ was the remainder of Taylor series expansion. When proceeding non-linear test of $z_{t}=\left(d \ln g d p_{t-1}, d \ln g d p_{t-2}, d u r b a n_{t}\right.$, durban $\left._{t-1}\right)$ in this study, the original assumption (linear) in equation (5) was first set, so that non-linearity existed when the original assumption was rejected. Under the condition of null hypothesis to test $\chi^{2}$ distribution with the statistic degree of freedom $3 \mathrm{~m}$, the statistic of $\chi 2$ distribution would be seriously distorted in small samples. Terasvirta suggested replacing it with $\mathrm{F}$ statistic. Under the condtion of null hypothesis, the gradual $\mathrm{F}$ distribution revealed the degree of freedom $3 \mathrm{~m}$ and $\mathrm{T}-4 \mathrm{~m}-1$, and then the conversion function $\mathrm{G}$ was confirmed as LSTR1 $(\mathrm{k}=1)$ or LSTR2 $(\mathrm{k}=2)$ (including ESTR). The specific function was selected depending on the following short-term sequential test.

$$
\begin{aligned}
& H_{04}: \beta_{3}=0 \\
& H_{03}: \beta_{2}=0 \mid \beta_{3}=0 \\
& H_{02}: \beta_{1}=0 \mid \beta_{2}=\beta_{3}=0
\end{aligned}
$$

When $\mathrm{P}$ value tested in $\mathrm{H}_{03}$ could strongly reject null hypothesis, LSTR2 or ESTR model could be selected; or, LSTR1 model could be selected.

\section{EXPERIMENTAL PROCESS AND RESULT OF STR MODEL}

\subsection{Variable selection and data acquisition}

1. Economic growth rate (GDP). Gross domestic product (100 million dollar) is often used for measuring the economic growth degree of countries or regions. To match with another two indicators in the empirical analysis, which are proportional indicators, and reduce the heteroscedasticity, the logarithmic differentiation of GDP, DINGDP is used as the economic growth rate.

2. Urbanization standard (Urban). Most literatures taking the weight of urban population in total population by the end of a year as the urbanization ratio could present the degree of population accumulation in metropolitises. Such an indicator is applied to this study.

3. Financial deepening (FIS). A lot of literatures measured financial deepening with total credit/GDP weight. Nonetheless, according to the viewpoints of Xiao et al. (1988), the process of financial intermediation in a restrained economy could generally be defined as the structural reform of bank autonomation, reduction of mandatory loan, and marketization of financial decision. With the strict control of financial system by the Chinese government, 
the financial reform gradually moved towards the abyssal zone after the $18^{\text {th }}$ National Congress of the Communist Party of China in 2012. It seems not to be suitable using the data of total credit/GDP in 1978-2012 for measuring financial deepening. Zhang Jun et al. (2005) indicated that the financial deepening degree of China could be comprehended as the commercialization of state-owned banks which indirectly correlated with the allocation ratio of bank advance between state-owned enterprises and various emerging enterprises. Accordingly, Chou Juan-dong et al. (2011) is referred in this study; but the distribution ratio of bank advance between state-owned enterprises and non-state-owned enterprises could not be directly calculated without the data of microenterprises, but merely the loan distribution between the two could be calculated. The weight of the loan of non-state-owned enterprises in GDP is then estimated to calculate the financial deepening degree in China. ${ }^{1}$ The specific equation is shown as financial deepening $=[(1$-gross industrial output value of state-owned enterprise/gross industrial output value)* various loan of financial insittutions]/GDP. The data of gross domestic product (100 million dollar), gross industrial output value of state-owned enterprises (100 million dollar), gross industrial output value (100 million dollar), and various loan of financial insittution (RMB) are covered. The fixed price converted from the correspondent output index $(1978=100)$ is applied to the merit index affected by the inflation. The data are acquired from China Economics, China Statistical Yearbook, China Industry Economy Statistical Yearbook, and Almanac of China's Finance and Banking. The years with missing data are made up with interpolation. The sequence diagram of indicators after the above processing is shown as below.

Figure 1 shows the smoother curves of economic level (LNGDP, the logarithmic of GDP) and urbanization standard (urban), which present stable increase. The financial deepening index appears as an increasing trend in 25 years, implying the annually increasing financial deepening degree; and the financial reform of the government is moving towards "abyssal zone", revealing the significant function of financial development in national economy. Apparently, such variation trend is closer to the actual situation in China that such indicators could be utilized in the successive model construction process.

Two assumptions are covered here. 1) Loan distributed from state-owned enterprises and the output value of such state-owned enterprises are proportional to the weight of gross industrial output value. 2) Total credit is merely considered to be distributed to state-owned enterprises and non-state-owned enterprises. 


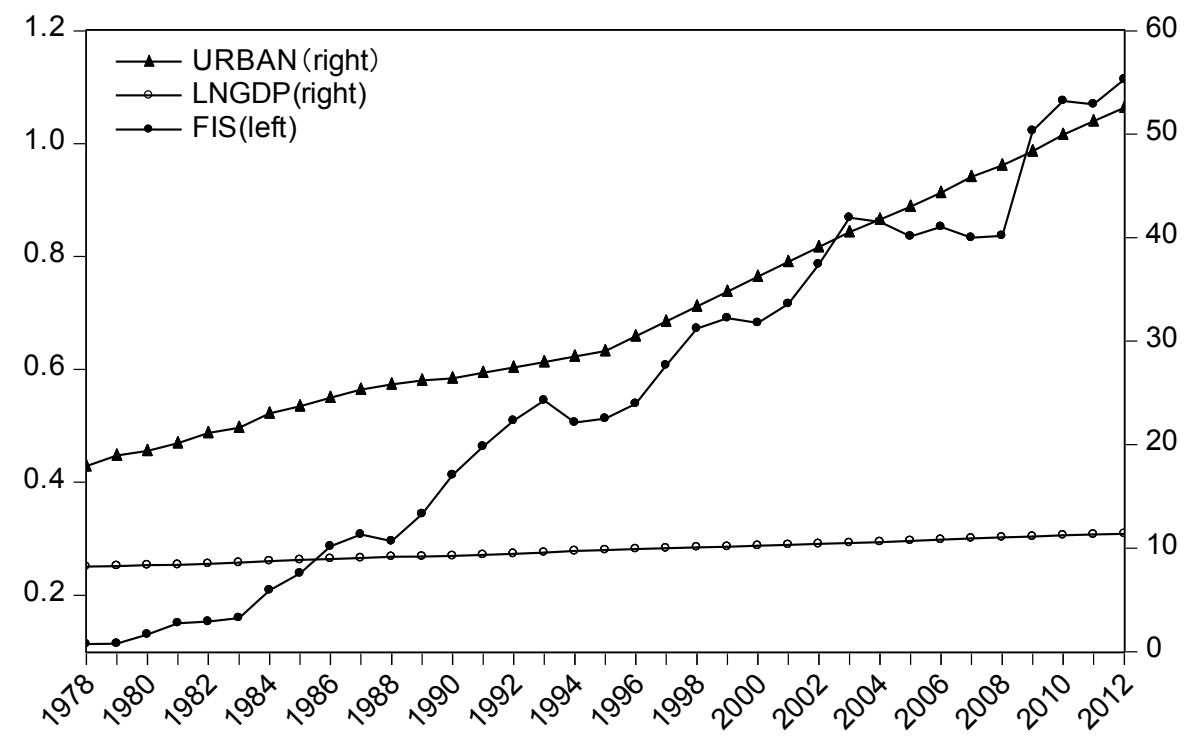

Figure 1. Time series of variables

\subsection{Stationary test of variable}

Generally speaking, stationary series are required to prevent "spurious regression" from appearing in time series; or they could not be directly used for Regression Analysis.

From the ADF test results (Table 1), Urban variable appears I (1) and FIS variable also appears I (0). ADF test of DINGDP variable shows I (0). Finally, the indicators of Durban and dlngdp are used for the empirical analysis.

Table 1. Stationary test of variables

\begin{tabular}{lccc}
\hline Variable & ADF test value & $\mathrm{P}$ & Test form \\
\hline FIS & -4.592 & 0.0059 & $(\mathrm{c}, \mathrm{t}, 8)$ \\
DINGDP & -3.801 & 0.0073 & $(\mathrm{c}, \mathrm{t}, 3)$ \\
Urban & 3.207 & 0.999 & $(\mathrm{n}, \mathrm{n}, 1)$ \\
Durban & -3.538 & 0.052 & $(\mathrm{c}, \mathrm{t}, 0)$ \\
\hline
\end{tabular}

Note: In ADF test (c, t, p), c stands for intercept, $\mathrm{t}$ for trend, and $\mathrm{p}$ for lag. The original assumption $\mathrm{H} 0$ shows unit root in the series. 


\subsection{Estimation procedure}

1. Confirmation of the number of model autoregressive lag order

For setting the STR model, all explanatory variables and the number of lag order covered in the model need to be confirmed. In consideration of the non-linear effect of urbanization on economic growth as well as the number of lag order of DINGDP and Durban, the rules are surely referred to Sensier and Osborn's (2002) approach. First, the third order of lag is the optimal, according to the test with VAR model, and the maximal number of lag order is set 3. Second, the final number of lag order is confirmed by measuring AIC, SBC, significance, DW, and $\mathrm{R}^{2}$. Based on above principles, $(2,3)$ is the optimal. However, Durban $(-3)$ is insignificant, and Durban $(-1)$ is insignificant in $(2,2)$. Further considering the factor of sample size, the number of lag order in AR of STR model is confirmed $(2,1)$.

\section{Identification of STR model}

The type of conversion function is determined by following the loop test rule of the previous $\mathrm{H} 04, \mathrm{H} 03$, and $\mathrm{H} 02$. Since the non-linear relationship of the effect of urbanization on economic growth is considered from the aspect of financial restraints, it is wondered whether the function path of urbanization on enhancing economic growth depends on the financial restraint degree. For this reason, the financial deepening index (FIS) is selected as the transition variable in this study.

The result (Table 2) shows the concomitant probability of $\mathrm{F}$ less than $5 \%$, revealing the non-linearity of the model. The concomitant probability of F3 is larger than it of F4 and F2 that the conversion function is confirmed as LSTR1.

$$
G\left(\mathrm{r}, \mathrm{c}, \mathrm{s}_{\mathrm{t}}\right)=\left[1+\exp \left\{-\gamma\left(\mathrm{s}_{\mathrm{t}}-\mathrm{c}\right) / \hat{\sigma}_{\mathrm{s}}\right\}\right]^{-1}, \gamma>0
$$

where $\mathrm{s}_{\mathrm{t}}$ is the transition variable, $\hat{\sigma}_{s}$ is the sample standard deviation of $\mathrm{s}_{\mathrm{t}}, \gamma$ is the slope coefficient, reflecting the conversion rate of conversion function in $(0,1)$, and positional parameter $\mathrm{c}$ is the critical value to confirm the state change.

Table 2. Linear assumption test and the selection of conversion function

\begin{tabular}{lccccc}
\hline $\begin{array}{l}\text { Statistic } \\
\text { transition } \\
\text { variable }\end{array}$ & F & F4 & F3 & F2 & $\begin{array}{c}\text { Model or type of } \\
\text { conversion function }\end{array}$ \\
\hline FIS(t)* & $2.0146 \mathrm{e}-02$ & $3.4031 \mathrm{e}-02$ & $2.1536 \mathrm{e}-01$ & $1.1938 \mathrm{e}-01$ & LSTR1 \\
\hline
\end{tabular}

Note: F statistic is proposed by Granger and Terasvirta (1993) to test the linear assumption; F4, F3, and F2 correspond to $\mathrm{H} 04, \mathrm{H} 03$, and $\mathrm{H} 02$ statistics, presenting the median being the concomitant probability of statistic. 
3. Estimate result of model

Since the initial value is primary for the parameter estimate in LSTR1 model, the initial value is repeatedly computing algorithm (The specific process is referred to Appendix A5 of Hendry (1995) and Yi Xin-jian and Deng Ke-bin (2008), Application of Time Series to Econometrics. It is not re-stated here.) with BFGS. The interval of $\Upsilon$ and $\mathrm{c}$ is set $[0.5,10]$ and $[0.21,1.11]$, respectively, and the step length 0.03 . The initial estimates of $\Upsilon$ and $\mathrm{c}$ are shown in Table 3.

Table 3. Initial estimate of smoothing parameter and positional parameter

\begin{tabular}{ccc}
\hline Least residual sum of square & Initial estimate of $\gamma$ & Initial estimate of $\mathrm{c}$ \\
\hline 0.0025 & 10.000 & 0.4269 \\
\hline
\end{tabular}

According to Terasvirta's (2004) point of view, the initial value being in the structural interval should be paid attention to when two parameters were estimated; when it appeared beyond the interval, the initial value of the non-linear optimization was not suitable; otherwise, it could be suitable. Accordingly, the initial value estimated in this study could be regarded as the optimal initial value. Substituting the initial values of $\Upsilon$ and $c$ in equations (1) and (2), the recursive Newton-Raphson could be applied to calculate the maximal value of the likelihood function and further estimate the model parameter. Hendry (2005) proposed to delete insignificant coefficients till all coefficient being significant. As a result, the estimated result, equation (8), is acquired after several tries.

$$
\begin{aligned}
& \begin{array}{l}
d \ln g d p_{t}= \\
{\left[0.110-0.595 * \operatorname{dlngdp}_{\mathrm{t}-2}+0.072 \text { durban }_{\mathrm{t}}\right.}
\end{array} \\
& +\left(-0.058+1.086 \mathrm{dlngdp}_{\mathrm{t}-1}-0.046 \text { durban }_{\mathrm{t}}-0.031 \text { durban }_{\mathrm{t}-1}\right) * \mathrm{G}\left(\gamma, \mathrm{c}, \mathrm{s}_{\mathrm{t}}\right)+\mathrm{e}_{\mathrm{t}} \\
& {[0.087] \quad[0.065] \quad[0.030]} \\
& G\left(\gamma, c, s_{t}\right)=\frac{1}{1+e^{-\frac{487711\left(s_{t}-0.3792\right)}{\hat{\sigma}_{F I S}}}, \gamma=487.71(\mathrm{p}=1.000), \mathrm{c}=0.3792(\mathrm{p}=1.000), \hat{\sigma}_{F I S}-0.309} \\
& \text { adj_R } \mathrm{R}^{2}=0.752, \mathrm{AIC}=-8.150, \mathrm{SC}=-7.726, \mathrm{RSS}=0.0025, \hat{\sigma}_{\text {resid }}=0.015
\end{aligned}
$$

Equation (8) presents that the effect of domestic urbanization on economic growth appears non-linearity with the financial deepening degree. $\Upsilon$ stands for the conversion rate, and $\mathrm{c}$ is the positional parameter and locates in the set interval. Figure 2 shows the model simulation, where presents favorable simulation effect. 4. Robustness test of model 
Plot of Time Series $1984-2012.0, T=29$

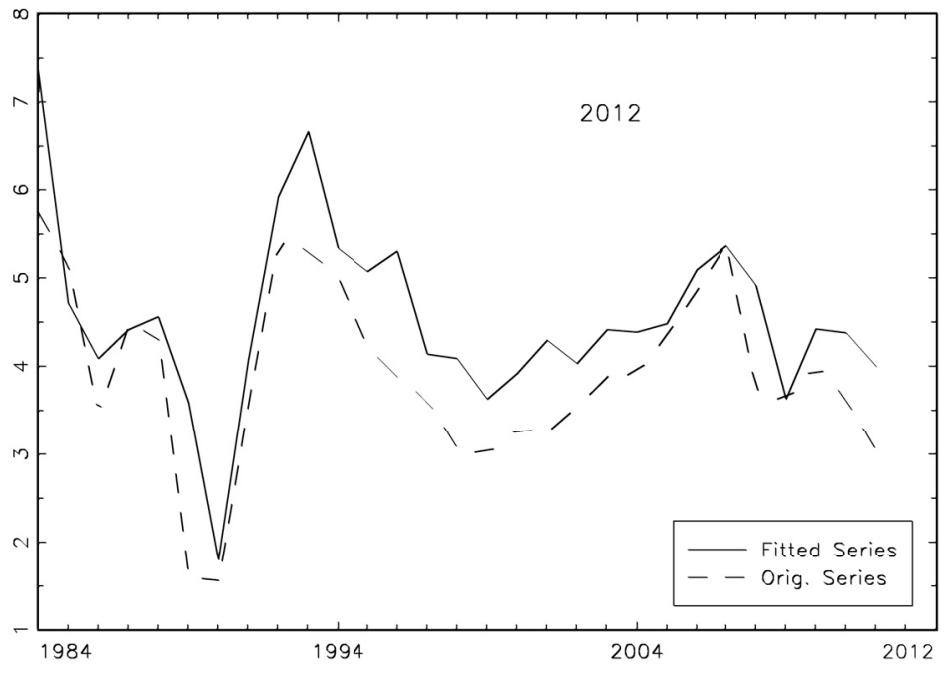

Figure 2. Sequence diagram of original and simulation data

Plot of Time Series $1984-2012.0, T=29$

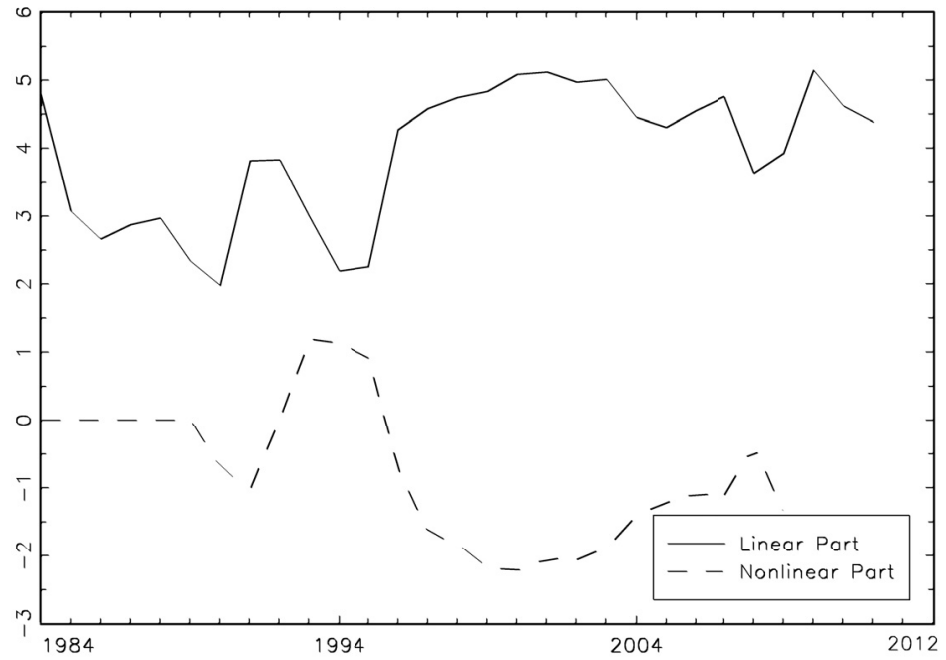

Figure 3. Sequence diagram of linearity and non-linearity 
(1) Model residuals test

As shown in Table 4, $\mathrm{P}$ value in F statistic is larger than 10\% at lag 1-4 stages, demonstrating the series correlation not existing in the residual. $\mathrm{P}$ value in ARCH-LM $\chi^{2}$ statistic at lag 1-3 stages is larger than 10\%, showing the inexistence of autoregressive heteroscedasticity as well as the inexistence of general model setting bias. (Referring to Application of Time Series to Econometrics (2008), translated by Yi Xin-jian and Deng Ke-bin.) The concomitant probability in JB statistic is larger than $10 \%$ that the residual conforms to the normal distribution. ADF test presents no unit root under the $1 \%$ level that the residual is stationary. In this case, economic growth and urbanisation standard appear non-linear cointegration. ("Non-linear cointegration" is referred to Ye A-zhong, 2002).

Table 4. Serial correlation of residual, heteroscedasticity and normality test

\begin{tabular}{lccc}
\hline Lag stage & Autocorrelation LM test & $\begin{array}{c}\text { Heteroscedasticity } \\
\text { ARCH-LM test }\end{array}$ & Normality test \\
\hline & $\mathrm{F}(\mathrm{p})$ & $\chi^{2}(\mathrm{P})$ & $\mathrm{JB}=1.8944(\mathrm{p}=0.3878)$ \\
1 & $1.7749(0.1994)$ & $0.2487(0.6180)$ & resid_ADF $=-2.604(5 \%$ \\
2 & $0.8049(0.4644)$ & $0.5075(0.7759)$ & $=-1.94)$ \\
3 & $0.4802(0.7012)$ & $0.8074(0.8477)$ & \\
\hline
\end{tabular}

(2) No added non-linearity test

No added non-linearity test inspects other non-linearity existing in the model by changing transition variables. Table 5 shows the concomitant probability in F statistic larger than $5 \%$ when using other variables as the transition variable, revealing the inexistence of residual non-linearity, which could be reflected in Figure 5.

Table 5. Model residual non-linearity test

\begin{tabular}{lcccc}
\hline Transition variable & F & F4 & F3 & F2 \\
\hline LNGDP_d1 (t-1) & $7.5258 \mathrm{e}-02$ & $1.4739 \mathrm{e}-01$ & $8.0998 \mathrm{e}-02$ & $1.9295 \mathrm{e}-01$ \\
LNGDP_d1 (t-2) & $3.8961 \mathrm{e}-01$ & $8.4461 \mathrm{e}-01$ & $8.4788 \mathrm{e}-02$ & $1.5511 \mathrm{e}-01$ \\
Urban_d1 (t) & $3.7717 \mathrm{e}-01$ & $6.9598 \mathrm{e}-01$ & $1.1080 \mathrm{e}-01$ & $1.9329 \mathrm{e}-01$ \\
Urban_d1 (t-1) & $1.3299 \mathrm{e}-01$ & $4.6779 \mathrm{e}-01$ & $5.1218 \mathrm{e}-01$ & $2.4977 \mathrm{e}-03$ \\
\hline
\end{tabular}

(1) Stability test of parameter

Taking time $t$ as the new transition variable, the stablility of variable parameters is further observed; the original assumption shows the parameter with stablility. Table 6 displays the statistic concomitant probability larger than $10 \%$ that the original assumption cannot be rejected; the parameter estimated in the model presents better stablility. Meanwhile, Figure 4 shows the trend of conversion 
function and transition variable, and Figure 5 presents the curve diagram of conversion function.

Table 6. Stability test of parameter

\begin{tabular}{lccc}
\hline $\begin{array}{l}\text { Original assumption } \\
\text { (parameter with stablility) }\end{array}$ & $\mathrm{H} 1$ & $\mathrm{H} 2$ & $\mathrm{H} 3$ \\
\hline All parameters & 0.0467 & $\mathrm{NaN}$ & $\mathrm{NaN}$ \\
Except durbant-1 & 0.1384 & $\mathrm{NaN}$ & $\mathrm{NaN}$ \\
Except durbant & 0.1057 & 0.1487 & 0.3933 \\
Except dlngdp_dt-1 & 0.0509 & $\mathrm{NaN}$ & $\mathrm{NaN}$ \\
\hline
\end{tabular}

Note: The values in the table are $\mathrm{P}$ values, $\mathrm{NaN}$ is resulted from the matrix calculating reverse inexistence.

Plot of Time Series 1984-2012.0, T=29

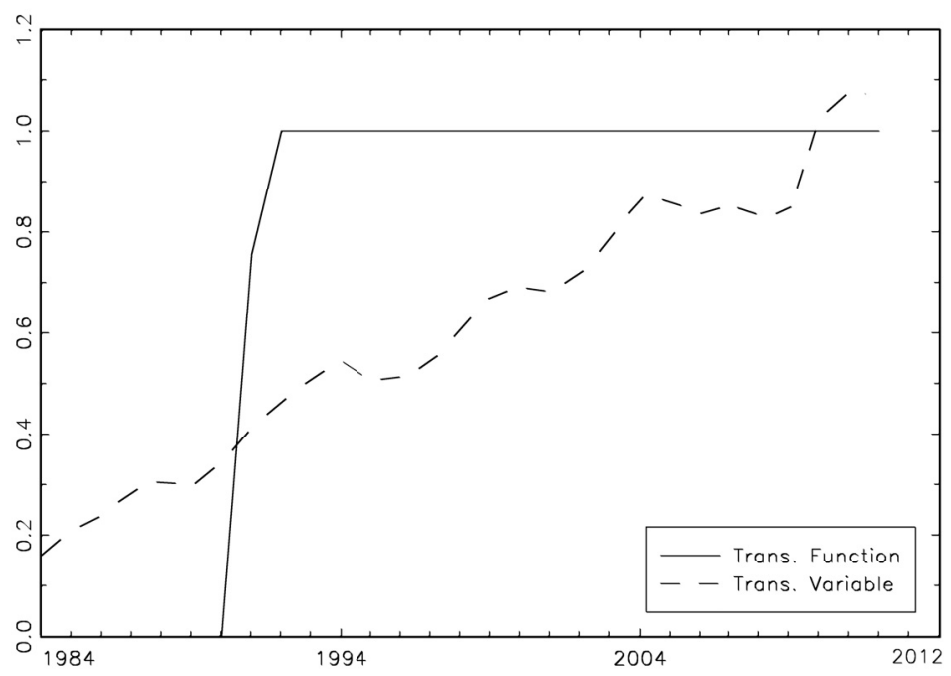

Figure 4. Sequence diagram of conversion function and transition variable

(2) Explanation of model result

From the estimate result of equation (8), the parameters are close to the economic theory, implying the long-term non-linear effect of domestic urbanization standard on economic growth, and such effect changes with the financial deepening degree. The smooth parameter $\Upsilon$ stands for the conversion rate of model, and the final estimate is 487.71, explaining that the effect of urbanization on economic growth changes with the financial deepening degree, and the conversion rate is faster. The final estimate of positional parameter C 0.3792 locates in 
Crossplot G(FIS(t))

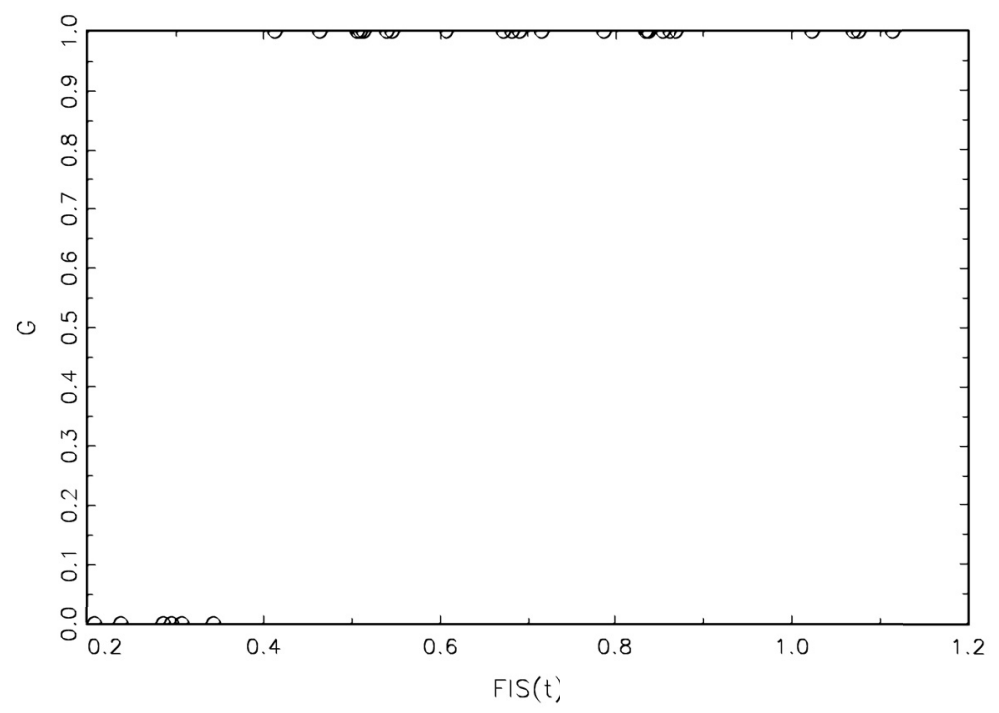

Figure 5. Curve diagram of conversion function

the range of $[0.21,1.11]$, revealing the better desirability of the non-linear STR model. When the financial deepening degree is low (less than 0.3792), the change of urbanization standard in the contemporary economic growth rate appears the impact factor 0.072 , the average long-term impact factor is $0.04514(=0.072 /$ $(1+0.595))$ and significant under the $10 \%$ level, showing the benefit of increasing urbanization standard to economic growth. When the financial deepening degree is high (larger than 0.3792), the contemporary impact factor appears 0.026 , which is $63.89 \%$ less than the previous mechanism, and the long-term average impact factor is 0.0098 . When the financial deepening degree appears around the positional parameter, the effect of urbanization on economic growth presents smooth transition between two mechanisms, and the mechanism conversion rate is relatively faster. Figure 4 and Figure 5 show the favorable explanation of LSTR1 model. From the simulation effect, the dynamic character of original data and simulation data are basically consistent, showing that the model could favorably explain the dynamic non-linear relationship between urbanization and economic growth.

Figure 5 shows that the long-term relationship between domestic urbanization standard and economic growth presents non-linearity with regime switching because of the financial deepening degree. The turning point of the conversion function $\mathrm{G}$ occurs at $\mathrm{c}=0.3792$ (in 1990), revealing the asymmetric feature be- 
tween urbanization standard and economic growth when FIS is larger or less than the value. Figure 6 displays the sequence diagram between conversion function and transition variable. On one hand, it reflects the probability $(0 \leq \mathrm{G} \leq 1)$ of economic growth rate at distinct economic state with time going on; on the other hand, it reflects the function of non-linearity being reinforced after 1990 .

\section{CONCLUSION AND SUGGESTION}

Aiming at domestic data samples in 1978-2012, the existing researchers' approaches are utilized for calculating the financial deepening degree. Non-linear Smooth Transition Regression Model (STR) is then applied, in which the financial deepening is regarded as the transition variable to estimate the urbanizational economic growth effect and precede the robustness test of the estimate. The conclusion is organized as the following:

(1) The effect of urbanization standard on economic growth in China is obviously asymmetric, showing stronger non-linear transfer and state dependence. Taking the structural financial deepening index as the transition variable, it is found that the state dependence between urbanization standard and economic growth appears different features with the financial deepening strength, which is divided into high mechanism stage and low mechanism stage. The effect of urbanization on economic growth converts between two mechanisms, and the contemporary effects of urbanization on economic growth reduces $63.89 \%$, comparing high mechanism stage with low mechanism stage, and the longterm effect even appears negative.

(2) The effect of urbanization on economic growth is non-linear, and not both remain constant functional relationship. The short-term impact factor is lower in high mechanism than in low mechanism; the long-term impact mechanism reveals positive in low mechanism but negative in high mechanism. It implies that the effect of urbanization on economic growth would increase and then decrease with the financial deepening degree. It is consistent with Henderson (2003) that an optimal value exists in the effect of urbanization on economic growth. According to this study, it seems to exceed such an optimal value. Nevertheless, the financial system in China in 1990 appeared in the conversion of plan and market economy that the financial industry presented remarkable difference in the urbanizational economic effect in such two mechanisms. However, it showed that urbanization expansion could not be blindly pursued as the push of economy would be eliminated from long-term and short-term effects. Making sure of a reasonable urbanization standard according to domestic financial development policies is especially important. 
Based on the above conclusions, the following suggestions are concluded for policies. It is necessary to study the financial support policy and financial product suitable for domestic urbanization development. There has not been a mature and suitable financial support model for domestic urbanization development. Blindly supporting urban construction with capitals is not scientific and would simply result in large quantity of "ghost towns". (Economic Information, August 16, 2013. After the media exposed the empty Ordos City, more "ghost towns" and "sleeping towns" were reported in Changzhou in Jiangsu Province and Shiyan in Hubei Province. The investigation discovered that the real-estate market bubble was expanding from first-line cities to third-line inland cities and towns.) 2. Enhancing urbanization quality and allowing financial industry offering excellent services for urbanization development are the keys in "new" style urbanization. The effect of urbanization on economic growth has great correlations with the financial deepening degree. Irrationally and blindly supporting urbanization construction would obstruct and delay the promotion of economic growth.

\section{ACKNOWLEDGEMENTS}

Funded project: Sponsored project of innovation base for graduate education of Quantitative Economics in Fujian Province; Humanities and Sociology Research funded project (11JYA790048) from the Ministry of Education; Fujian Province Soft Science Research project (2012R0058); Fujian Province Social Science Research project (FJ2015 C241); Fujian Province Department of Education project (JA11273S). We are grateful to have sponsors from the above projects for this study.

\section{REFERENCES}

Chen Ke-jia and Zang Yong-shen (2013). Urbanization, economic growth mechanism of action in Fujian Province. Urban Problems, (5), 57-61.

Chou Juan-dong, He Feng-juan and Yi Yong-mei (2011). Explore financial repression, financial constraints, financial liberalization and financial deepening interaction. School of Economics and Management at Northwestern University, (6), 55-63.

Fan Zhao-bin and Zuo Zheng-qiang (2004). Regional financial development and urbanization in Guangdong province. Economic Review, (12), 31-34.

Földvári, P., van Leeuwen, B. and Didenko, D. (2015). Capital formation and economic growth under central planning and transition: A theoretical and empirical analysis, ca. 1920-2008. Acta Oeconomica, 65(1), 27-50.

Granger, C. and Terasvirta, T. (1993). Modelling Nonlinear Economic Relationships [M]. Oxford University Press, Oxford.

Henderson, J.V. (2000). The effects of urban concentration on economic growth. National Bureau of Economic Research., 8, 47-71. 
Henderson, J.V. (2003). The urbanization process and economic growth: The so-what question [J]. Journal of Economic Growth, 8(1), 47-71.

Hendry R. (2005). Lavoisier and Mendeleev on the elements. Foundations of Chemistry, 7, 31-48.

Hendry, D.F. (1995). Dynamics Econometrics [M]. Oxford University Press.

$\mathrm{Lu} \mathrm{Ke}$ and Zhao Yang (2013). Innovative research in new urbanization commercial banking group financial products. Journal of Zhongnan University of Economics and Law, (06).

Lucas, R.E. Jr. (2004). Life earnings and rural-urban migration. Journal of Political Economy, 112(S1), S29-S59.

Lucas, R.E. Jr. (1988). On the mechanics of economic development. Journal of Monetary Economics, 122(1), 3-42.

Mckinnon, R. I. (1973). Money and capital in economic development [M]. Brookings Institution Press..

Meng Yin-li (2003). Financial deepening, economic growth and urbanization effects analysis. Quantitative and Technical Economics Research, (04), 138-140.

Moomaw, R.L. and Shatter, A.M. (1996). Urbanization and economic development: a bias toward large cities? [J]. Journal of Urban Economics, 40(1), 13-37.

Qi Xin (2013). Effect of urbanization on economic growth-based on the decomposition analysis of economic growth effect and spatial spillover effect. Statistics \& Information Forum, (06), $45-50$.

Sensier, M., Osborn, D. and Öcal, N. ( 2002). Asymmetric interest rate effects for the UK real economy. Oxford Bulletin of Economics and Statistics, 64(4), 315-339.

Shen Kun-rong and Jiang Rui (2007). How urbanization affects economic growth in China. Statistical Research, (06), 9-15.

Terasvirta, T. (2004). Smooth transition regression modeling [J]. Applied Time Series Econometrics, (2), 22-42.

Tian Dong-lin (2013). Make good financial services around new-style urbanization. Macroeconomic Management, (10), 54-55.

Uandt, R.E. (1958). The estimation of the parameters of a linear regression system obeying two separate regimes [J]. Journal of the American Statistical Association, (284), 873-880.

Williamson, J.G. (1988). Migration and urbanization. Handbook of Development Economics, (1), 425-465.

Wu Hong-lin (2012). Research on China's financial development, economic growth and urbanization relations. Journal of Anhui University of Technology, (3), 289-293.

Xiang Zheng, Wu Shih-lei and Zhao Xin (2013). Urbanization pulling effect on economic growth. Economic Review, (4), 70-73.

Xiao and Shao Fu-jun (1988). Economic Development in the Financial Deepening. Joint Publishing, Shanghai.

Xu Xiao-qin and Yuan Kai-hua (2013). Mechanism and characteristics of urbanization driven by economic growth - Empirical evidence from provincial panel data. Inquiry Into Economic Issues, (5), 134-140.

Ye A-jhong (2002). Non-parametric test with non-linearity cointegration. Prediction, 21(1), 69-79.

Yuan Xiao-chu (2013). Financial support for new-style urbanization construction. Study and Exploration, (08), 122-124.

Zhang Jun and Jin Yu (2005). Analysis on relationship of deepening financial intermediation and economic growth in China. Economic Research, 11(34), 5.

Zhou Yi-xing (1982). Regularity of urbanization and GNP relations. Population and Economy, (1), 152-168. 